\title{
MANIFESTAÇÕES PATOLÓGICAS EM ESQUADRIAS
}

\author{
SCHUCH, DAIANA C. \\ Arquiteta e Urbanista \\ Universidade do vale do Rio dos Sinos \\ Rio Grande do Sul; Brasil \\ daiana_schuch@hotmail.com
}

\section{EHRENBRING, HINOEL Z}

Doutorando em Engenharia Civil

Universidade do vale do Rio dos Sinos

Rio Grande do Sul; Brasil

hzamis@unisinos.br

\author{
CHRIST, ROBERTO \\ Doutor em Engenharia Civil \\ Universidade do vale do Rio dos Sinos \\ Rio Grande do Sul; Brasil \\ rchrist@unisinos.br
}

\section{RESUMO}

As esquadrias estão presentes em todas as nossas edificações onde desempenham um papel importante com relação à habitabilidade dos usuários. As manutenções em esquadrias devem ser realizadas periodicamente para que seja possível o controle dos agentes como, ventilação, iluminação, água, poeiras e insetos, conforme definição da NBR 10821-1 (ABNT, 2017). A falta de manutenção acaba prejudicando a funcionalidade das esquadrias e a sua manutenabilidade acaba sendo maior com o passar do tempo. Este trabalho buscou evidenciar as manifestações patológicas mais recorrentes, nas esquarias instaladas na região Sul do Brasil. Em um período de dois anos, foram analisadas 200 esquadrias de duas tipologias e três materiais distintos (madeira, alumínio e PVC). Foram realizadas análises estatísticas através de análise de variância para evidenciar se as manifestações patológicas encontradas possuem influência com relação ao tipo e aos materiais que são compostas. Os resultados encontrados puderam identificar que a madeira, por ser um material natural e orgânico, está suscetível a presença de pragas que podem desencadear diversas manifestações patológicas decorrentes desta condição, que apresentam valores que variam de 39\% à 59\% . O alumínio, por sua vez, apresentou o percentual de $63 \%$ à $71 \%$ para as avaliações de infiltração e desgaste de componentes. Já o PVC apresentou resultados de $3 \%$ a $21 \%$ quanto às infiltrações porém, o desprendimento de componentes tem resultados de $57 \%$ à $72 \%$. Sendo assim é possível concluir que nenhum dos materiais está isento de apresentar manifestações patológicas e o controle por meios de industrializações pode minimizar os problemas, e que alguns itens ainda merecem uma grande atenção para melhor desempenho das esquadrias entregues aos consumidores.

Palavras-chave:Esquadrias, vedações, estanqueidade, permeabilidade.

\section{ABSTRACT}

The frames are present in all of our buildings where they play an important role in relation to the users' habitability. The maintenance of frames must be performed periodically so that it is possible to control agents such as ventilation, lighting, water, dust and insects, as defined in NBR 10821-1 (ABNT, 2017). The lack of maintenance ends up impairing the functionality of the frames and their maintainability ends up being greater over time. This work sought to show the recurrent pathological manifestations in the scaffolding installed in the southern region of Brazil. In a period of two years, 200 frames of two types and three different materials (wood, aluminum and PVC) were analyzed. Statistical analyzes were carried out through analysis of variance to show whether the pathological manifestations found have an influence in relation to the type and materials they are composed of. The results found could identify that the wood, being a natural and organic material, is susceptible to the presence of pests that can trigger several pathological manifestations resulting from this condition, which present values that vary from 39\% to 59\%. Aluminum, in turn, presented the percentage of $63 \%$ to $71 \%$ for the evaluation of infiltration and wear of components. PVC, on the other hand, showed results of $3 \%$ to $21 \%$ regarding infiltrations, however, the detachment of components has results of $57 \%$ to $72 \%$. Thus, it is possible to conclude that none of the materials is exempt from presenting pathological manifestations and the control by means of industrialization can minimize the problems, and that some items still deserve great attention for better performance of the frames delivered to consumers.

Keywords: Frames, seals, tigtness, permeability 


\section{INDRODUÇÃO}

Segundo Nazário e Zancan (2011), o termo "patologia" é derivado do grego (pathos - doença, e logia - ciência, estudo) e significa "estudo da doença". Na construção civil pode-se atribuir patologia aos estudos dos danos ocorridos em edificações. Sendo assim, a patologia se resume ao estudo da identificação das causas e dos efeitos dos problemas encontrados em uma edificação, elaborando seu diagnóstico e correção.

As esquadrias desempenham fundamental papel nas edificações e para isso é necessário estar atento as manifestações patológicas que possam ser desenvolvidas ao longo da sua vida útil. Frente a demanda por habitação, cabe à indústria da construção civil focar-se na maximização da construtibilidade e minimização do tempo e do custo de execução, sem deixar de garantir o desempenho desejável à edificação. Esse esperado crescimento de eficiência dos processos de produção tem sido impulsionado, também, pelas novas tendências do mercado, como o aumento da competitividade e a maior exigência dos consumidores. Uma importante consequência deste conjunto de fatores é o aumento da preocupação com a qualidade da habitação por parte dos clientes desse setor (ZECHMEISTER, 2005).

Para que uma esquadria apresente qualidade ela deve atender os requisitos exigidos pela NBR 10821-2 (ABNT, 2017) através de níveis de desempenho desejados e são eles: Permeabilidade ao ar; Estanqueidade à água; Resistência à cargas uniformemente distribuidas; Operação e manuseio e Segurança nas operações de manuseio. Estes requisitos devem ser atendidos para as esquadrias de qualquer tipo de material, e estão ligados tanto a segurança quanto ao conforto do usuário.

Segundo a $\mathrm{ABCIC}$ "Estanqueidade à água de chuva é uma das propriedades ou requisitos mais dificeis de serem bem atendidos por uma janela", (ABCIC, 1991). Como define a norma NBR 10821-2, para que seja estanque à água "a janela não pode apresentar vazamentos que provoquem o escorrimento de água pelas paredes ou componentes sobre os quais esteja fixada, quando submentida a vazão mínima de água de $2 \mathrm{~L} / \mathrm{min}$ por bico e às pressoões de ensaio correspondentes às regiões do Brasil", (ABNT, 2011). Desta forma este trabalho tem por objetivo identificar quais as manifestações patológicas mais comuns encontradas nas esquadrias analisadas nos três tipos de materiais citados: Madeira, Alumínio e PVC, nas duas tipologias: Maximar e Correr. Esta pesquisa foi realizada através de inspeção visual e os resultados que serão apresentados neste artigo.

\section{MANIFESTAÇÕES PATOLOGICAS EM ESQUADRIAS}

\subsection{Madeira}

A madeira é o primeiro materiais utilizado para a confecção de caixilhos em edificações (BRUNA et al., 1991). Tendo em vista a importância que desempenhou nas mãos de artesões, na confecção de portais medievais e igrejas é o material mais tradicional e que possui o efeito estético mais sofisticado. como principais vantagens permitir a utilização de técnicas de pinturas em seu acabamento, e um custo reduzido desde que sejam aplicados em modelos padronizados. No entanto, dependendo da escolha do tipo de madeira, e opção por produzir algo mais original pode elevar seu custo (BRUNA, 1991).

O Brasil é um país com inúmeras florestas, possui grandes áreas plantadas e uma das maiores reservas nativas do planeta. No Brasil, mesmo com esse destaque no cenário mundial, o consumo per capita de madeira ainda é muito baixo comparado a outros países. De acordo com o arquiteto Ricardo Dias, professor da Universidade Estadual de Maringá (UEM), países europeus como Estônia, Letônia, Finlândia e Austria, o consumo per capita é de 1,27 metros cúbicos por habitante por ano, enquanto que no Brasil, o número é de 0,108. (Dias, 2017).

Há uma variedade de madeiras que podem ser utilizadas como matérias-primas para a fabricação de esquadrias, dentre as quais devem ser analisados basicamente três critérios, a maleabilidade, a resistência e a umidade. Para executar uma esquadria com qualidade é necessário que a madeira esteja completamente seca, caso contrário, a madeira continuará com o processo de secagem mesmo depois da esquadria instalada, podendo ocorrer deformações irreversíveis (SILVA; SILVA, 2007). Existem no Brasil diversas empresas que produzem esquadrias em nível industrial. Em número reduzido, existem as que continuam produzindo suas esquadrias de forma artesanal. (HOFFMANN, 2012).

As esquadrias de madeira proporcionam um toque requintado e confortável. Adaptam-se às condições do clima pois são bons isoladores térmicos evitando assim a condensação de umidade em sua superfície numa situação de grande diferença de temperatura entre os ambientes que a esquadria separa (HUTH, 2007).

A principal desvantagem da madeira é a sua vulnerabilidade de grande parte das espécies, quando expostas a condições climáticas adversas. A umidade, radiação solar e agente biológico, interfere na estrutura da madeira acarretando primeiro a perda de seu valor estético e posteriormente sua degradação (RODRIGUES, 2015). Outra desvantagem é que este material pode apresentar variações de volume (retração ou inchamento), em função da variação da umidade, mesmo depois de trabalhadas, apesar de existirem diversas maneiras de proteger a madeira e minimizar os efeitos causados por agente naturais. A aplicação de substâncias químicas é a melhor forma de protegê-la e aumentar sua vida útil, existem 
uma vasta linha de produtos disponíveis no mercado com diferentes características. Porém, a aplicação destes produtos deve ser rotineira, o que acaba se tornando uma desvantagem (RODRIGUES, 2015).

O processo de fabricação obedece uma ordem e alguns critérios, sendo que o primeiro deles refere-se ao nível de umidade no processo da secagem da madeira. A etapa seguinte é o corte e fresamento onde as tábuas começam a ganhar a forma de perfil de madeira que vai constituir o caixilho. Em seguida é o tratamento anti-ataques de microorganismos feito com produtos químicos usualmente feitos pelo processo de submersão (TRAVASSOS, 2010). As madeiras são estocadas para um novo processo de secagem ao ar livre onde se reduz ao mínimo a possibilidade de empenamento.

Em relação ao acabamento após as etapas anteriores, o tratamento passa por máquinas que eliminam possíveis deformações da superfície da madeira como plainas, desempenadeiras, calibragem de medidas, lixamento superficial até chegar ao bitolamento necessário. Com as peças acabadas, desenhadas com todos os encaixes necessários, processa-se a montagem dos quadros e folhas e a colagem de todo o material. A etapa de colagem é uma das principais responsáveis pela durabilidade da montagem dos caixilhos e uma das que mais problemas podem trazer (TRAVASSOS, 2010).

O desempenho de uma janela depende das características físicas, econômicas, psicofísicos e artísticos. Depende ainda do sistema de juntas e acessórios, da altura a ser instalada na edificação, da posição na fachada, do meio ambiente onde estará inserida (condições externas) e outras situações definidas pelo projeto arquitetônico da edificação (FERNANDES, 2004). A durabilidade natural das madeiras é uma característica extremamente relativa, pois depende não somente de fatores decorrentes da própria natureza do material, espécie lenhosa, cerne ou alburno, presença de taninos, óleos e resinas em seus vasos lenhosos, como também de fatores externos, relacionados às condições do ambiente de emprego, umidade, temperatura, arejamento, etc. (HUTH, 2007).

\subsection{Alumínio}

O histórico do uso das esquadrias de alumínio no país já é antigo, desde 1940 pode-se encontrar fábricas com produção de esquadrias deste material, porém não existiam perfis extrudados, ou seja, as chapas eram cortadas e trefiladas (uma espécie de dobras) até chegar ao tipo de perfil desejado. Este processo era demorado e muitas vezes ocorriam defeitos que apresentavam dobras imprecisas, sendo melhorado somente em 1952 quando os Estados Unidos difundiram ao mundo a técnica de extrusão (ASA ALUMINIO, 2006). Extrusão, de acordo com a NBR 6599 (ABNT, 2000), é o processo metalúrgico que consiste na deformação plástica a quente do material, fazendo-o passar, pela ação de um pistão, através de um orifício e uma matriz que apresenta o contorno da secção do produto a ser obtido.

O uso do alumínio é difundido no mundo devido às suas características, tais como: aparência limpa e moderna, é um material leve, facilitando sua execução e não acrescentando muita sobrecarga à edificação. Além disso, possui defesa natural à ação da água e, consequentemente, à corrosão, propiciando maior longevidade quando em comparação à esquadrias de metais e de madeiras mais simples, necessitando assim uma menor manutenção. A fim da obtenção de um melhor caráter estético ou de uma maior vida útil, pode facilmente receber pintura eletrostática ou anodização, conferindo ao material final uma maior resistência frente às intempéries (ASA ALUMINIO, 2006).

O alumínio mostrou-se extremamente vantajoso para a construção civil como matéria-prima para esquadrias, devido às características como leveza, função estrutural, baixa manutenção e fabricação de esquadrias nas mais variadas tipologias, com design atualizado e geometria livre. O material é resistente à corrosão e, quando submetido aos tratamentos superficiais, tais como a anodização ou pintura apropriada, sua resistência é ampliada, além de não oxidar como o ferro e não perder o brilho. É exatamente pela durabilidade que o emprego do alumínio tem crescido na confecção de esquadrias. (HUTH, 2007).

Uma das principais características do alumínio é sua alta reciclabilidade. Depois de muitos anos de vida útil, segura e eficiente, o alumínio pode ser reaproveitado, com recuperação de parte significativa do investimento e economia de energia, como já acontece largamente no caso da lata de alumínio. Além disso, o meio ambiente é beneficiado pela redução de resíduos e economia de matérias-primas propiciadas pela reciclagem (HUTH, 2007).

Além de possibilitar vários acabamentos e ser de um material extremamente durável, a esquadria de alumínio é geralmente muito precisa e estanque (com exceções das janelas padrão de má qualidade que são vendidas em diversos centros de construção no país). O alumínio oferece muitas opções de acabamento e não enferruja, sendo adequado para construções à beira-mar, por exemplo. Este material é extremamente leve, facilitando a fabricação, instalação e funcionamento do produto, além disso, diminui o peso nas estruturas principais dos edifícios (RODRIGUES, 2015).

Segundo a CEHOP (2017), as esquadrias de alumínio podem ser confeccionadas em escala industrial ou sob encomenda, com perfis estrudados, sólidos ou abertos, tubulares ou fechados e semi-tubulares (parcialmente fechados). Podem também ser fabricadas pela associação dos perfis com laminados de alumínio e chapas.

Segundo Yazigi (2004), o grande número de fabricantes de esquadrias de alumínio, torna a qualificação de fornecedores uma tarefa complexa, levando em conta as dificuldades em se obter dos projetistas um detalhamento de projeto que permita a contratação de serviços com critérios técnicos e econômicos bem definidos. Segundo o autor, fabricantes que 
se encontram em um estágio tecnológico adiantado oferecem o serviço de projeto das esquadrias com estudo de soluções técnicas e economicamente vantajosas para a obra. Partindo das especificações dos projetistas, esses fabricantes têm melhores condições de otimizar o projeto e o uso dos perfis, por meio de sistemas informatizados, assegurando o cumprimento das normas técnicas nas fases de projeto, produção e instalação.

$\mathrm{Na}$ fase de projeto podem-se identificar algumas possíveis manifetações patológicas. É importante atentar para alguns itens na execução do projeto arquitetônico, tais como, definir esquadrias dentro da linha do fabricante e não misturar linhas, evitar esquadrias com ângulos agudos, prever condições de manutenção, conservação e limpeza das esquadrias, evitando locais inacessíveis, utilizar esquadrias preferencialmente, com contramarco, entre outros. O problema mais comum encontrado é a infiltração de água, que quando feita uma instalação correta pode ser facilmente detectado e resolvido. O contramarco, quando corretamente instalado, é o principal item que garante que não haja infiltrações (ALBUQUERQUE, 2017)

\subsection{PVC}

O PVC foi descoberto em 1835 por Regnault quando descobriu o cloreto de vinila, composto no qual o PVC é fabricado. No início do século XX, na Alemanha, começou a pesquisar novas utilizações. No entanto apenas em 1955, na Alemanha, foi utilizado o PVC para confecção de esquadrias (SANTOS, 2004). O Desenvolvimento das esquadrias de PVC ocorreu basicamente na década de 70, sendo o auge na década de 80 , com participação de aproximadamente $45 \%$ no mercado alemão. Este desenvolvimento foi acompanhando pela Áustria e Bélgica praticamente na mesma época. A partir de então, o produto se propagou pela Europa e pelos Estados Unidos, assumindo parcelas significativas de uso nesses mercados (ABCIC, 1991, ).

O Policloreto de Vinila (PVC) é obtido a partir do etileno, um dos subprodutos do petróleo, que representa $43 \%$ de seu peso, combinado com o cloro retirado do cloreto de sódio, o sal de cozinha, que representa $57 \%$ de seu peso. Esses dois recursos naturais, sal e petróleo (ou gás natural) são à base da fabricação dos componentes do PVC (GODOI, 2005). O etileno é obtido através dos processos de refinamento do petróleo, já o cloro provém da eletrólise, reação que consiste na passagem de uma corrente elétrica por uma certa quantidade de água salgada obtendo o cloro (SANTOS, 2004).

O PVC é um material de alta resistência a intempéries, maresias e agentes biológicos possuindo longa durabilidade. Pode ser aplicado nas mais adversas condições climáticas, pois possuem a propriedade de ser bom isolante térmico. Além de todas estas vantagens, o PVC ainda pode ser pigmentado de diversas cores, atingindo os padrões estéticos desejáveis (HUTH, 2007).

As esquadrias de PVC apresentam diversas vantagens em relação às esquadrias fabricadas com outros materiais. Segundo a ABCIC, "Em quaisquer condições climáticas, e de oscilações de temperatura ou umidade, os perfis de PVC mantêm-se estáveis em suas dimensões, vedando e resistindo adequadamente a cargas extremas de ventos e chuva". Outra vantagem dessas esquadrias está na forma como elas são produzidas. Por sua fabricação ser por um processo altamente industrializado, é possível garantir às esquadrias precisões milimétricas, além da ligação dos perfis por meio de soldagem, eliminando o uso de cantoneiras, parafusos ou grampos (ABCIC, 1991).

Segundo Rauber (2012), um aspecto importante que faz crescer a demanda da utilização do PVC é a conscientização das pessoas acerca da necessidade de preservação de florestas e matas. Diante dessa nova preocupação os empreendedores têm se empenhado em buscar alternativas no ramo de esquadrias que aliem tecnologia à funcionalidade e atendam às necessidades dos clientes. Ademais, importante notar que a escassez de madeiras nobres em razão do crescente controle mais rigoroso do desmatamento, leva inevitavelmente ao uso de novos materiais e nesse caso o PVC se destaca por causa da sua qualidade, versatilidade e acessível produção (RAUBER, 2012).

As esquadrias são produzidas a partir de perfis extrudados, os quais possuem aço galvanizado em sua estrutura interna, o que aumenta sua resistência. Existe uma grande variedade de tipologias de perfis, que se adaptam aos projetos garantindo um produto final qualificado. Outro ponto positivo das esquadrias de PVC é que são excelentes isolantes termo acústicas e não propagam chamas, sendo bastante utilizadas em países da América do Norte e Europa há bastante tempo (HUTH, 2007).

Cabe mencionar, que o consumo energético na produção e transformação do PVC é um dos mais baixos, se comparado com o de outros materiais utilizados na construção civil, na confecção dos caixilhos, tais como ferro alumínio, madeira e aço. O consumo bruto para a fabricação do PVC representa, em média, menos de $0,25 \%$ da quantidade de petróleo bruto extraído no mundo (SANTOS, 2004).

A ligação dos perfis que formam os quadros das esquadrias acontece em fábrica através de soldas térmicas, com isso não ocorre a descontinuidade nos cantos das peças como no caso da madeira e alumínio, consequentemente a esquadria apresenta maior estanqueidade à água. (SANTOS, 2004). O PVC pode ser produzido com diversas cores e padrões, dentre eles pode assemelhar-se a esquadrias de madeira, visto que ele pode ser dimensionado e pintado de forma a se parecer esteticamente com ela (OLIVEIRA, 2012). 
Uma desvantagem do uso do PVC é que, ainda que seja difícil sua combustão, quando inflama o material produz um gás que contém ácido clorídrico $(\mathrm{HCl})$, o qual é altamente tóxico e prejudicial à saúde Desse modo, há de se observar com atenção o uso de esquadrias de PVC em ambientes fechados (SANTOS, 2004). As esquadrias de PVC devem atender aos requisitos da BS EN 12608, que trata da especificação os perfis, e a esquadria deve atender a especificação para a fabricação de janela e portas conforme NBR 10821 (ABNT, 2017)

As esquadrias de PVC se destacam no mercado por apresentarem um elevado padrão de qualidade, resistência e durabilidade, aspectos garantidos através do seu processo de produção altamente industrializado (TRIKEM S.A, 2000). A ABCIC (1991,) destaca que a utilização do PVC na fabriação de esquadrias tem apresentado bons resultados, visto que essas apresentam uma boa resistência mecânica, adaptando-se até mesmo em condições climáticas extremas.

A ASPEC, Associação Brasiliera dos Fabricantes de Sistemas, Perfis e Componentes para Esquadrias de PVC, é uma entidade sem fins lucrativos que congrega os fabricantes comprometidos com qualidade de seus produtos e desenvolve competência para antecipar as transformações do mercado, da tecnologia e da legislação, contribuindo para que a cadeia produtiva seja representativa e atualizada, fomentando a ética, a leal concorrência e o respeito ao consumidor, (ASPEC, 2020).

Através do Programa Setorial da Qualidade (PSQ), a ASPEC, tem como seu principal objetivo criar mecanismos específicos que possam garantir a qualidade das esquadrias de PVC comercializadas no Brasil e que apresentem um desempenho satisfatório que atenda as necessidades dos usuários e que não afete a isonomia competitiva dos fabricantes (ASPEC, 2020).

Falhas durante o processo de instalação das esquadrias nas obras são geralmente a origem de grande parte das manifestações patológicas nas esquadrias, não necessariamente sendo um problema próprio do produto (ABCIC, 1991). As esquadrias também podem apresentar problemas de desempenho, afetado principalmente pela escolha do processo e das soluções adotadas para a instalação. Este tipo de manifestação pode ocorrer através de deformações no quadro da esquadria, perda de prumo, nível e esquadro das folhas e perda de material de vedação à estanqueidade. A má especificação de projeto das esquadrias é outro fator que pode afetar diretamente o desempenho das mesmas (LUCINI, 2011,).

Conforme a ASPEC, esquadrias que não atendem os programas de qualidade existentes podem também apresentar diversas manifestações patológicas tais como: corrosão em parafusos e componentes metálicos que comprometem o desempenho mecânico e a estética do produto; problema de infiltração e estanqueidade; janelas com folhas soltando devido à baixa resistência das articulações; rupturas nos cantos soldados (ASPEC, 2020).

\section{METODOLOGIA}

O presente estudo tem caráter exploratório e quantitativo para identificar as principais manifestações patológicas encontradas nas esquadrias dos seguintes materiais: Madeira, Aluminio e PVC. Para isso foram analisadas 200 esquadrias, no período de dois anos, que passaram por inspeções visuais para verificar as manifestações patológicas apresentadas nelas. As inspeções foram realizadas sempre da mesma forma, pela parte interna, avaliando as partes das esquadrias onde os itens avaliados foram listados em um check list e avaliados e citados nos resultados. Todas as janelas inspecionadas foram registradas no estado do Rio Grande do Sul, em cidades distintas. As inspeções ocorreram sempre no perído da manhã ou da tarde onde era possível ter maior visibilidade das manifestações patológicas encontradas. Nenhumas das esquadrias ou componentes foram removidos para análise em laboratório. Todas as verificações se basearam no que foi verificado in loco, sem considerar o tempo de instalação, orietanção solar de fachadas, manutenções preventivas e/ou reparatórias, no entanto nenhuma edificação possuia mais de 10 anos.

\section{RESULTADOS}

Os resultados encontrados serão apresentados nos gráficos e imagens abaixo, conforme a tipologia e o material utilizado na produção das esquadrias e os itens avaliados seguiram o mesmo padrão de inspeção e um check list de avaliação para a obtenção dos resultados necessários para esta avaliação. As Figura 1 e Figura 2 apresentam os resultados das principais manifestação patológicas encontradas nas esquadrias de madeira do tipo maximar e janela do tipo de correr. 
Figura 1 - Manifestações patológicas evidenciadas nas esquadrias de madeira do tipo maximar.

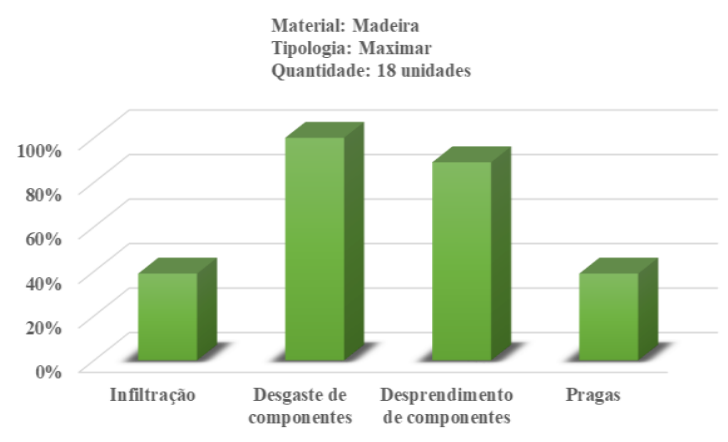

Figura 2 - Manifestações patológicas evidenciadas nas esquadrias de madeira do janela de correr.

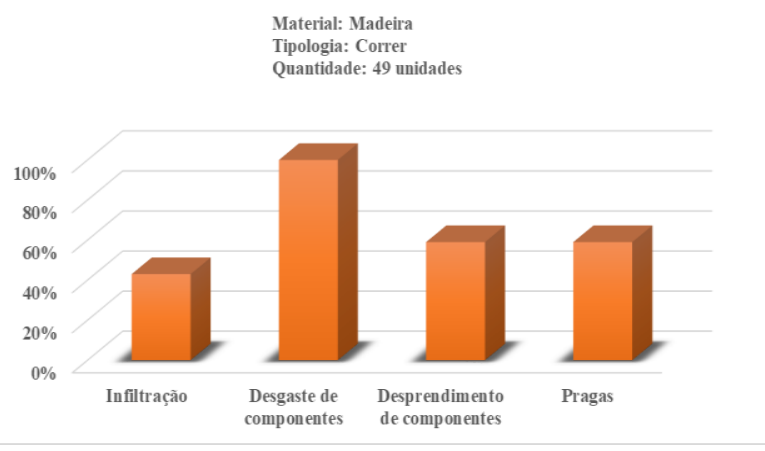

As manifestações patológicas encontradas são: infiltração, desgaste de componentes, desprendimento de componentes e ação de pragas. O primeiro item avaliado foi a infiltração que foi encontrado os resultados de $39 \%$ em esquadrias maximar e $43 \%$ de casos em esquadrias de correr. As infiltrações podem ocorrer tanto por conta dos desgastes do material, obstrução dos drenos ou ainda por instalações inadequadas. E o mais díficil é saber se elas estão de fato sendo por conta de problemas do produto ou por interfaces da fachada. Muitas vezes essa situação se confunde, pois um vão preparado adequadamente, com a base regularizada e com pingadeira em toda a sua superficie de base e o uso de polímetros de boa qualidade evitam que esse tipo de manifestação comprometa a vida útil das esquadrias, mas caso essas premissas não sejam respeitadas aliado com a má qualidade da execução da edificação, a falta de cuidado na instalação e produtos de baixa qualidade sem controle, não há dúvidas de que acarretará no aparecimento de manifestações patológicas graves e até irreversíveis.

$\mathrm{O}$ desgaste de componetes tem índices alarmantes e que comprometem totalmente a funcionalidade e segurança das esquadrias. Estamos tratando de um percentual de $100 \%$ dos casos inspecionados nas duas tipologias, e isso pode nos levar a entender que a qualidade dos componentes está diretamente relacionada à qualidade da esquadria, sendo assim o que está sendo entregue aos usuários não atende adequadamente às normas de desempenho em vigor. Muitas vezes esses componetes podem ser facilmente trocados, mas há casos pode não ser possível. Itens como trilhos não são de fácil substituição e isso gera a condição de ter a vida útil do produto findada. Além dessa manifestação patológica podemos ainda ter o desprendimento de componentes, conforme imagem 1, que pode gera risco a vida dos usuários. Não é incomum termos situações como essa, onde parte das esquadrias se desprendem e já não é mais possível manter o desempenho e qualidade das esquadrias. Neste caso da imagem a atampa da caixa de persiana desprendeu gerando diversos problemas, como aumento de ruídos dentro do ambiente, sensação de insegurança quando às demais partes da esquadria, vulnerabilidade para entrada de insetos, entre outros. Os percentuais de casos que foram encontrados são de $89 \%$ nas esquadrias maximar e de $59 \%$ nas esquadrias de correr. O desgate pode ser um fator que leva ao desprendimento de componentes, mas também a falta de controle na produção, a utilização de produtos de baixa qualidade para fixações dos componentes também pode contribuir para essas ocorrências.

A madeira ainda apresenta uma manifestação patológica distinta do aluminio e PVC, por se tratar de um material natural e orgânico, fica sujeita às ações de pragas e insetos, coisa que não ocorre nos outros dois materiais, sendo que $39 \%$ de casos foram encontrados em janelas maximar e 59\% nas janelas de correr. A falta de tratamento químico contínuo, para prevenção das pragas é um dos grandes fatores para o surgimento desse tipo de condição, conforme já foi dito por um autor, essa situação pode ser verificada na imagem 2 nas folhas das venezianas, que foram comidas por cupins e acabaram expostas foram perdendo suas partes e com isso as infiltrações ocorrendo, e as manifestações patológicas cresceram. Enquanto os cupins fragilizam as partes, abrem caminhos para que essas partes que começam a ter buracos, permita a penetração da água e comece o processo de apodrecimento da madeira que fica exposta e sem tratamento. Sendo assim uma manifestação patológica desencadeia outras e depois de um determinado período não é mais possível indetificar o principal agente causador dos danos. E situações como essa geram condições de necessidade de substituição da esquaria, pois o reparo já não é mais possível.

Se a madeira não reeber tratamentos químicos constantes, esse tipo de manifestação patológica não cessa e vai sendo somatizada com outras decorrentes da fragilização. 


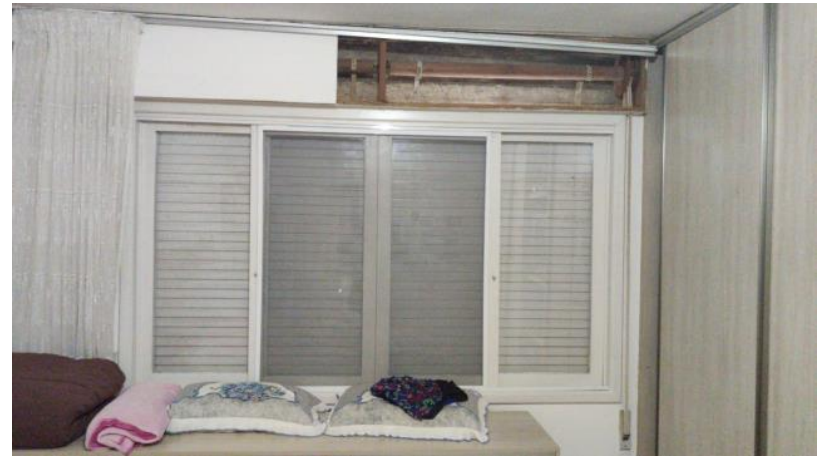

Imagem 1- desprendimento de tampa de caixa de persiana

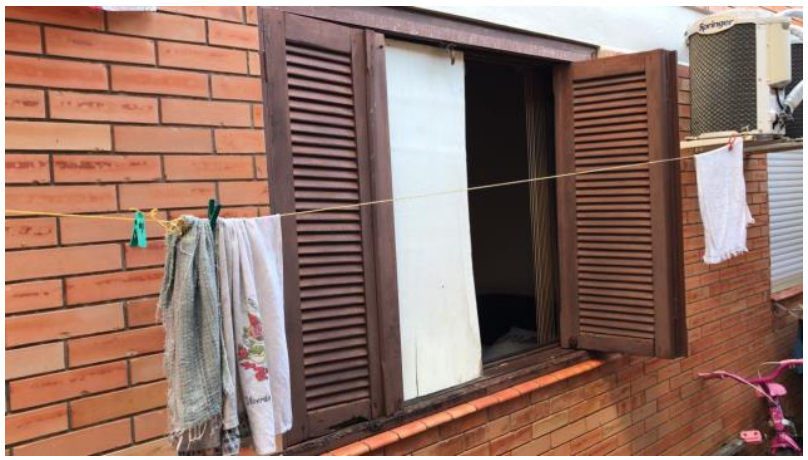

Imagem 2 - ação de pragas tipo cupim na parte inferior

As Figura 3 e Figura 4 apresentam os resultados das principais manifestação patológicas encontradas nas esquadrias de madeira do tipo maximar e janela do tipo de correr. Quando analisado os resultados para as esquadrias de alumínio, também é registrado percentuais muito elevados para as manifestações patológicas analisadas acima, conforme registrado nas figuras 3 e 4 , sendo correspondente as tipologias maximar e correr respectivamente.

Figura 3 - Manifestações patológicas evidenciadas nas esquadrias de alumínio do tipo maximar.

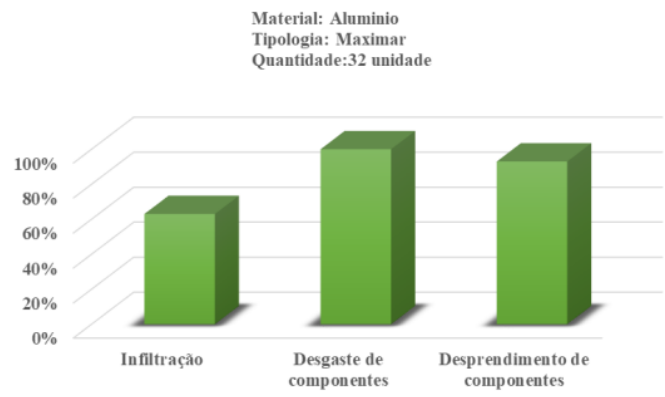

Figura 4 - Manifestações patológicas evidenciadas nas esquadrias de alumínio do tipo de correr.

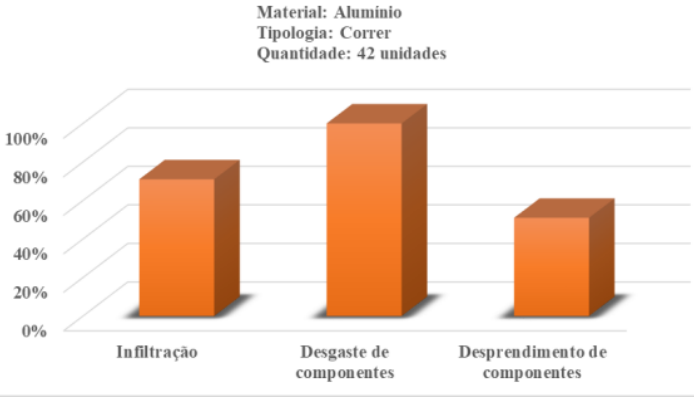

Nas esquadrias de alumínio os valores foram de $63 \%$ para maximar e $71 \%$, de correr para os casos de infiltração, e isso pode estar diretamente relacionado à falta de contramarcos que segundo os fabricantes e alguns autores é imprescindível para a melhor condição de instalação e estanqueidade. No entanto também podemos afirmar que adquirir produtos que estejam certificados em programas de controle de qualidade, que tenham passado por testes podem reduzir estas estatisticas encontradas. Na imagem 3 podemos verificar que a estanqueidade é de fato um fator primordial em uma esquadria, pois ter escorrimento de água nas paredes internas, além de ser incomodo é sem dúvida uma condição que não pode ser tolerada e está prevista em norma e deve ser atendida para que isso não ocorra. Essas infiltrações levam a problemas na pintura, o piso pode ser danificado e até mesmo a mobilia. Outro resultado expressivo e negativo é o desgaste de componentes, que garantem a funcionalidade, vedação, qualidade e segurança do produto, tais como: trilhos, roldanas, escovas de vedações e maçanetas, que apresentaram 100\% de danos, tanto nas esquadrias maximar quanto nas de correr. Ter partes da sua esquadria desgastado gera situações de impossibilidade de uso, uma maçaneta por exemplo desgastada, pode gerar situações de impossibilidade de travameto ou de abertura de uma esquadria. Escovas de vedação gastas antes do tempo previsto para a troca não são incomuns de serem encontradas, assim como trilhos que são gastos por desregulagem das folhas da esquadria, nos casos de janelas de correr, também os braços de janelas maximar que ficam raspando contra a folha e vão sendo corroídas e, que com o passar do tempo podem levar à ruptura deste item.

E por último o desprendimento de componentes que já foram citados em janelas de madeira é outro item que demanda atenção pelos índices elevados. Foi encontrado $93 \%$ de casos em maximar e $51 \%$ em janelas de correr. Conforme imagem 4 podemos entender que um desprendimento de uma parte da esquadria, ou quiçá toda ela não é algo que podemos ignorar quando estamos falando de manifestações patológicas. Os resultados elevados devem ser amplamente discutidos pelos fabricantes, uma vez que eles geram risco a vida dos usuários. Neste caso parte do marco da folha soltou e consquentemente o vidro fica solto, e o risco a vida do usuário é grande. Neste caso a falta de qualidade de montagem do produto é evidente, sendo que ao manusear o produto a peça se soltou. 


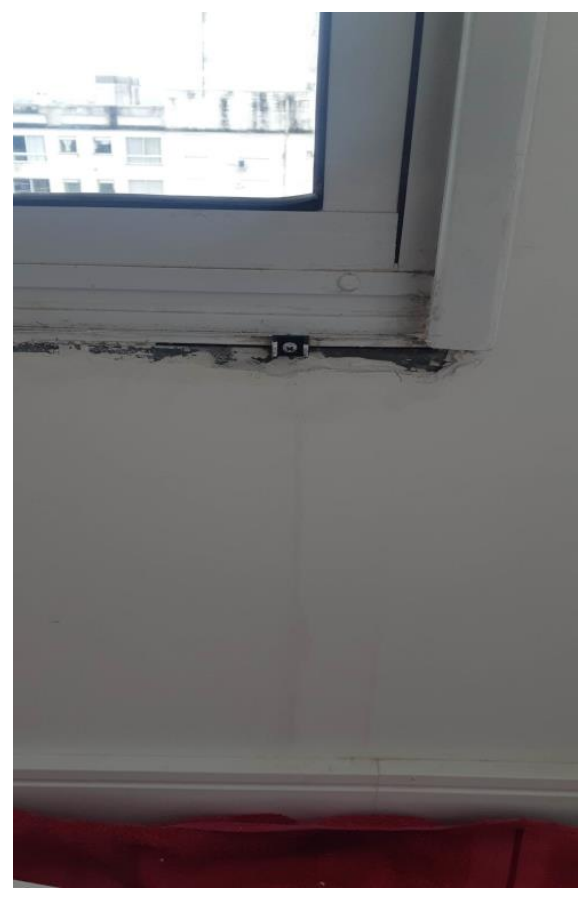

Imagem 3 - infiltração

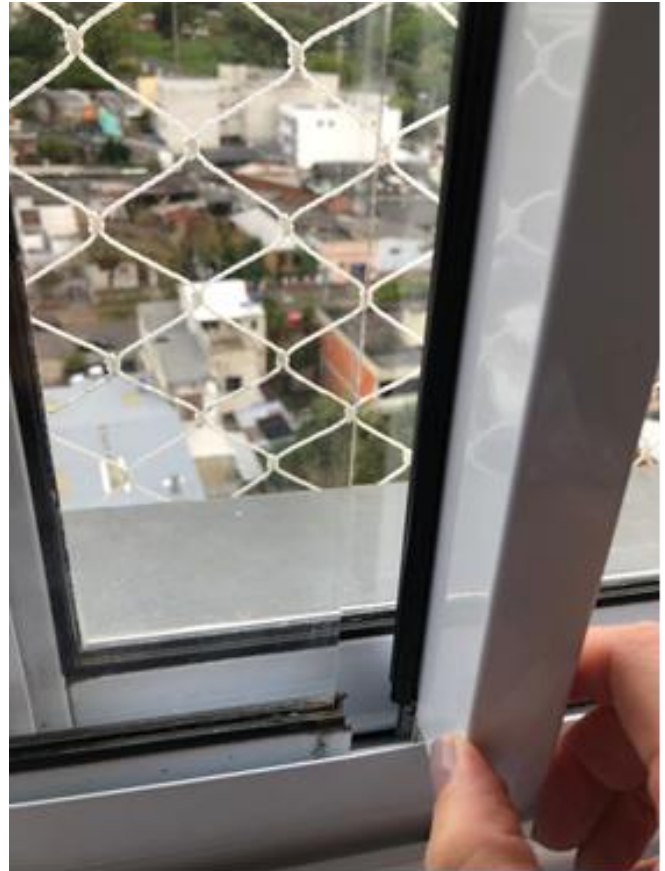

Imagem 4- desprendimento de componente

E por último as figuras 5 e 6, são os resultados das esquadrias de PVC, onde os resultados são discutidos abaixo.

Figura 5 - Manifestações patológicas evidenciadas nas esquadrias de PVC do tipo maximar.

Material: PVC
Tipologia: Maximar
Quantidade: 30 unidades

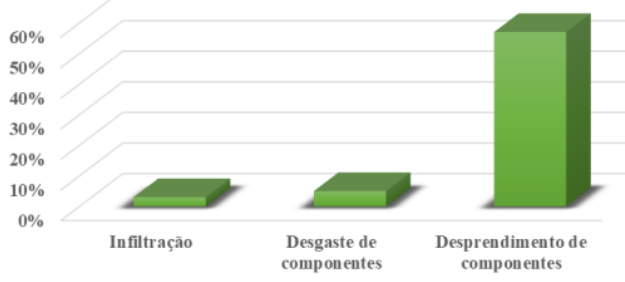

Figura 6 - Manifestações patológicas evidenciadas nas esquadrias de PVC do tipo de correr.

Material: PVC Quantidade: 29 unidades

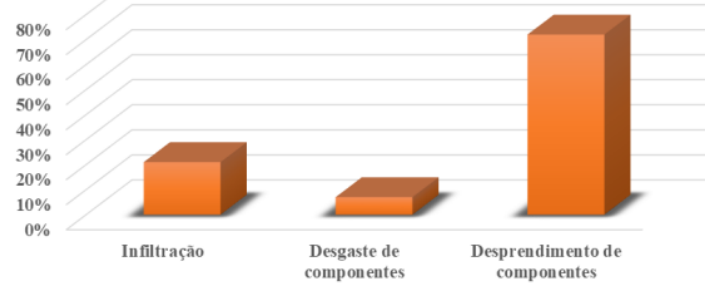

Nas figuras 5 e 6 estão os valores de $3 \%$ em maximar e $21 \%$ nas de correr para a manifestação patológica de infiltração. Esse baixo índice comparado com os demais materiais pode estar associado ao fato deste tipo de material ter cantos soldados e um controle mais industrializado da sua produção, tendo poucos itens para a montagem artesanal, como a colocação de vidros nas folhas da janela, gaxetas, escovas de vedação e a própria instalação. Como já dito por autores é um material que ainda pode ser considerado novo no mercado em relação aos outros dois e tem como característica um controle industrial maior, pois não é possivel unir as partes de uma esquadria de PVC apenas por encontros de cortes em 45 graus, ele necessita de termofusãopara se ligar. As infiltrações no PVC podem ter diversos fatores, como instalação inadequada, aplicações insuficiente de polímeros de vedação, união de 2 esquadrias em cantos que não recebem o devido cuidado na instalação, entre outros fatores. Na imagem 5 podemos verificar um caso de união de duas esquadrias em 90 graus que não recebeu a devida vedação e infiltrações geraram condições desagradáveis além de ter uma desvalorização da imagem do produto, e essa condição por exemplo não está ligada à produção do produto e sim à instalação inadequada.

No item desgaste de componentes temos valores realmente baixos, de 5\% e 7\% nas janelas maixmar e de correr, respectivamente. $\mathrm{O}$ controle de componentes é fator de análise nos programas de qualidade de produtos (PSQ) e isso pode estar relacionado aos baixos índices de manifestações patológicas, uma vez que para se obter o certificado de qualidade todos os itens da janelas são avaliados e se algum deles não atender ao PSQ, comprometem o selo qualidade de toda a esquadria. Porém existe no mercado esquadrias que utilizam componentes que não estão de acordo com as normas de qualidade e geram situações como da imagem 6 onde temos corrosão e ferrugem de parafusos que 
compromentem a fixação da esquadria e consequentemente a segurança do usuário. Nesta situação os parafusos enferrujaram, começaram a apresentar desgaste e posteriormente desprenderam do marco, permitindo a entrada de água na esquadria.

Agora quando trata-se da avaliação de desprendimento de componentes os valores surpreenderam por apresentar resultados elevados o que não ocorreu nos outros dois itens. Foi verificado que $57 \%$ das janelas maximar e $72 \%$ das janelas de correr tem desprendimento de componetes, sejam as gaxetas ou as maçanetas, itens que foram verificados nos check list pois foram os que apresentaram essa característica, o que vai na contramão de tudo que foi dito e verificado nos itens avaliados acima. Sendo assim deve ser avaliado as causas que levam a estes desprendimentos e os fabricantes devem ficar alerta a esses resultado e recomenda-se que alguma solução seja encontrada após a descoberta do porque essa situação ocorre com grande frequência. Isso pode ser consequencia de itens como acima citado que apresentam problemas e geram diversas outras manifestaões patológicas decorrentes de um problema em um item menor, mas não menos importante.

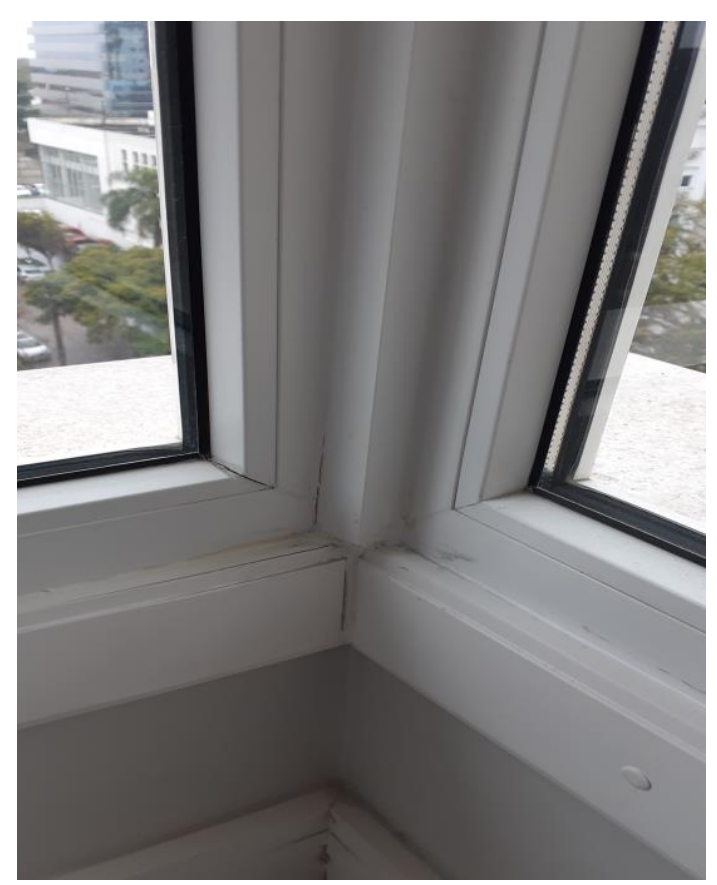

Imagem 5 - ligações entre cantos com infiltração

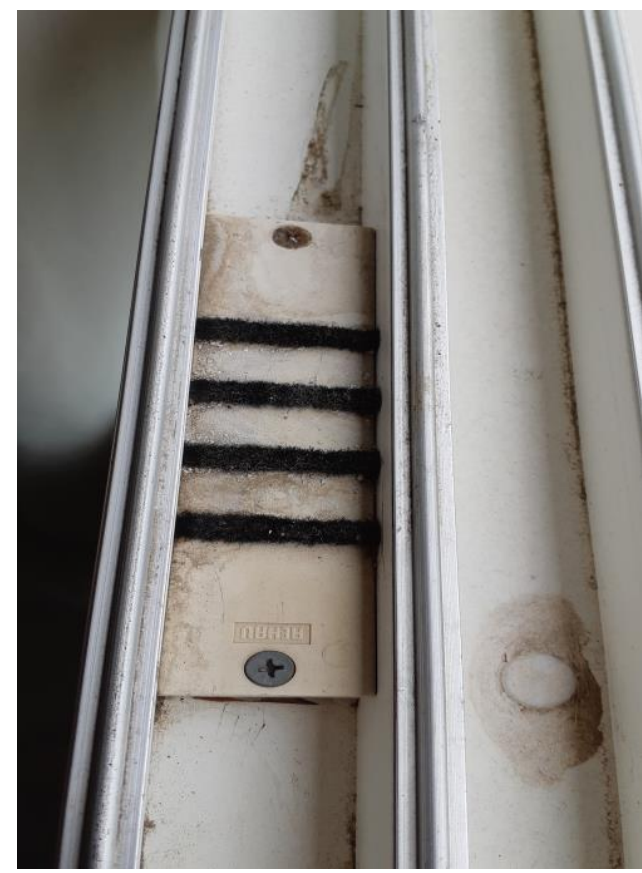

Imagem 6 - ferrugem em componente

\section{CONCLUSÃO}

Através dos resultados encontrados é possível verificar que as esquadrias de madeira e de alumínio apresentam valores mais elevados para algumas manifestações patológicas em relação às esquadrias de PVC. Que a instalação pode ser um fator muito comprometedor na qualidade dos produtos em toda e qualquer tipologia e material e que a industrialização das produções e programas de qualidade são necessários para que possa ter uma minimização de manifestações patológicas decorrentes de erro humano ou falta de cuidados dos fabricantes.

Esse trabalho buscou mapear algumas das manifestações patológicas mais comuns para que se possa ser discutido e avaliado esses problemas que causam tantos transtornos na vida dos usuários. Sendo assim novos trabalhos que possam surgir a partir deste estudo podem se aprofundar nos quesitos mencionados e ajudar a reduzir esses valores que foram elevados e assustadores. Conclui-se que ainda existem muitas questões a serem debatidas para que se possa atingir valores aceitáveis de falhas, de qualidade e de satisfação dos usuários. Programas de controle e de qualidade fazem muita diferença na qualidade dos produtos produzidos e entregue aos consumidores. Apresentar aos consumidores informações sobre a qualidade dos produtos pode ajudar a combater a utilização de produtos de baixa qualidade, e ajuda a valorizar as indústrias que levam a sério o que estão desenvolvendo e entendem suas responsabilidades frente ao mercado e ao consumidor. 


\section{REFERÊNCIAS}

ALBURQUERQUE, E.S.C. DE. Estudo Comparativo entre as Esquadrias de Aluminio e de PVC na Construção Civil. Trabalho de Conclusão de Curso para obter o grau de engenheiro civil. Universidade Federal da Paraíba. João Pessoa, 2017.

ASA ALUMÍNIO. Disponível em: http://www.asaaluminio.com.br/site/br/home/>, acesso em: 2 jan de 2015.

ASSOCIAÇÃO BRASILEIRA DE NORMAS TÉCNICAS. NBR 10821/1: Caixilhos para edificações - Janelas. Rio de Janeiro. 2011-A.

ASSOCIAÇÃO BRASILEIRA DE NORMAS TÉCNICAS. NBR 10821: Esquadrias externas para edificações. Rio de Janeiro. 2011-B.

ASSOCIAÇÃO BRASILEIRA DE NORMAS TÉCNICAS. NBR 6599: Alumínio e suas ligas - Processos e produtos Terminologia. Rio de Janeiro. 2000.

ASSOCIAÇÃO BRASILEIRA DE NORMAS TÉCNICAS. NBR 7199: Projeto, execução e aplicações de vidro na construção civil. Rio de Janeiro. 1989.

ASSOCIAÇÃO BRASILEIRA DA CONSTRUÇÃO INDUSTRIALIZADA. Manual técnico de caixilhos, janelas: aço, alumínio, vidros, PVC, madeira, acessórios, juntas e materiais de vedação. São Paulo: Pini, 1991.

ASEPEC, Associação Brasileira dos Fabricantes de Sistemas, Perfis, Componentes e Esquadrias de PVC, 2020.

BRUNA, P. et al. Manual técnico de caixilhos, janelas, aço, alumínio, madeira, PVC, vidros, acessórios, juntas e materiais de vedação. São Paulo : Pini, 1991.

DUARTE, P. Esquadrias e vidros na construção civil. Revista Vidro Impresso, $5^{\circ}$ ed. 2011.

FERNANDES, A. G. Esquadrias residenciais em madeira: contextualização de variáveis para otimização de projetos. 181 f. 2004. [TCC mestrado Engenharia Civil] Universidade Federal do Rio Grande do Sul, Porto Alegre, 2004.

GODOI, A. F. D. Esquadrias em PVC. Trabalho de Conclusão de Curso para obter o grau de engenheiro civil. Universidade Anhembi Morumbi, São Paulo, SP, 2005.

HOFFMANN, D. Aplicação para controle de orçamentos e pedidos de uma marcenaria. 73f. 2012. [TCC graduação Engenharia Civil]. Universidade Regional de Blumenau. Blumenau, 2012.

HUTH, P. Análise da relação custo-benefício de esquadrias externas para edificações residenciais com diferentes materiais. Trabalho de Conclusão de Curso de Engenharia Civil como requisito parcial para obtenção do grau de Engenheiro Civil. Universidade Regional do Noroeste do Estado do Rio Grande do Sul, Ijuí, RS, 2007.

LUCINI, H. C. Manual técnico de modulação de vãos de esquadrias. 1. Ed. São Paulo: Prini, 2001.

MOCH, Tiago. Interface esquadria/alvenaria e seu entorno: análise das manifestações patológicas típicas e propostas de soluções. Dissertação de Mestrado para obtenção do título de Mestre em Engenharia. Universidade Federal do Rio Grande do Sul, Porto Alegre, RS, 2009.

NAZARIO, Daniel; ZANCAN, Evelise C. Manifestações das patologias construtivas nas edificações públicas da rede municipal e Criciúma: Inspeção dos sete postos de saúde. 2011. 16f. Trabalho de Conclusão de Curso (Bacharel em Engenharia Civil) - Universidade do Extremo Sul Catarinense, Santa Catarina, 2011. Disponível em: <http://repositorio.unesc.net/bitstream/1/151/1/Daniel\%20Nazario.pdf>. Acesso em: 10 nov. 2016.

RAUBER. C. Análise da viabilidade para uma empresa de esquadrias de PVC. Trabalho de conclusão de curso apresentado no curso de Ciências contábeis do departamento de economia e contabilidade da Unijuí. Ijuí-RS. 2012. 
RODRIGUES, J. V. Esquadrias usadas na construção civil brasileira: características e execução. 69 f. 2015. [Trabalho de Conclusão de curso. Graduação Engenharia Civil]. Universidade Federal de Santa Maria. Santa Maria, 2015.

SILVA, C. C.; SILVA, J. C. Esquadrias em madeira para portas e janelas: Dossiê Técnico. Curitiba: Instituto Tecnológico do Paraná, 2007. 22 p.

SANTOS, W. B. D. A Inovação do PVC em janelas Estudo Comparativo entre PVC e alumínio, segundo as normas técnicas. Trabalho de conclusão de curso para o grau de engenheiro civil na Universidade Anhembi Morumbi, São Paulo, 2004.

SANTOS, J. A.; DUARTE, C. Degradação e proteção superficial da madeira em exterior. Corros. Prot. Mater., Lisboa, v. 32, n. 1, p.10-18, 01 mar. 2013.

TRIKEM S.A. Sistema em PVC na Cosntrução Civil. 2 ed. [s.1.], 1997. Esquadrias de PVC: tecnologia, especificação, projetos. São Paulo: ProEditores Associados, 2000.

ZULIAN, C. S. et al. Notas de Aula da Disciplina de Construção Civil: Esquadrias. 2002. 30 f. Curso de Engenharia Civil, Universidade Estadual de Ponta Grossa, Ponta Grossa, 2002.

DIAS, RICARDO. Brasil consome apenas $0,10 \mathrm{~m}^{3}$ de madeira por habitante ao ano www.madeiraeconstrucao.com.br, 2017. Disponível em http://madeiraeconstrucao.com.br/brasil-consome-apenas-010m\%C2\%B3-de-madeira-por-habitante-ao-ano/. Acesso 20 de fev. 2020 